Studia Anglica Posnaniensia 46/1, 2009

doi: 10.2478/v10121-009-0026-1

\title{
RHETORICAL EVALUATION OF SEVENTEENTH CENTURY PREFACES TO ENGLISH TREATISES ON MIDWIFERY
}

\author{
MARGARITA SÁNCHEZ-CUERVO
}

Universidad de Las Palmas de Gran Canaria

\begin{abstract}
This study tries to offer a rhetorical account of the main arguments and figures encountered in $17^{\text {th }} \mathrm{c}$. English prefaces, dealing with the art of midwifery and the delivery of children. I foreground a main causal argument wherein the author states the necessity for a treatise of this delicate nature and proposes the motives for its requirement. In doing so, some other reasonings support the causation and provide the reader with more evidence for a good performance at childbirth. In addition, the arguments are enhanced by the presence of some figures of communion that contribute to the rhetorical organisation, and help to portray the prologue as an expository discourse. The insistence on complying with the author's directions, and the urge not to follow some predecessors' work also suggests the new authority that the early modern English preface writer is acquiring.

\section{Introduction}

Prefaces, as a traditional site of conciliation between author and readership, and intended to stand outside the work they introduce, "offer frames for reading those works, frames that promise the reader a certain transparency of the ensuing text" (Evans 1999: 372). Indeed, my purpose in this study is to offer an account of the main argumentative schemes that can be observed in seven Early Modern English prefaces, or prologues, devoted to the childbirth process and care of prospective mothers, their possible maladies and further ministrations that may help to aid them. As to the etymology of the word, in the case of "prologue" it is 'before the word', from Greek logos; in the case of "preface" it is 'before speaking', from the Latin fas, 'that which founds', and the verb fari, 'to speak'. Moreover, these etymologies suggest that the prologue is "that which goes before the authoritative text, which stakes out for that text its cultural locus" (Evans 1999: 375).
\end{abstract}


The change in prefatory functions (Dunn 1994: 7) in the early Middle Ages makes known some complexities between the public and private sphere. By late antiquity, the rhetorical exordium has been largely outlined by its frequent doubling as an epistle dedicatory, as much as the request of the dedicatee allows the writer to shift responsibility to the requester. There exists an abdication of authority, and a general feeling of unworthiness before other precursors experienced by the authors of late Antiquity and the Middle Ages. The extent (Wogan-Browne et al. 1999: 7) to which medieval and modern notions of literary authorship differ can be observed in the prologue of the Middle English version of a surgical compendium, The cyrurgie (excerpt 1.10). This reflects on the role of a compiler, Guy de Chauliac, and on questions of textual transmission and intellectual traditions with considerable self-consciousness and sophistication. The cyrurgie is submitted to the authority of God as "supreme author of the eternal life of the soul as well of the flesh and its healing." By exposing a prose structure reminiscent of Latin manuals and compositions, de Chauliac asks God to oversee the beginning, the middle and the end of the work. The cyrurgie, as a compilation, sees itself as representing an addition to an authoritative tradition of medical writing that the prologue summons by using the common rhetorical topos of deference. As I will point out below, the authors of the prologues under analysis employ this topos as well.

By the late Middle Ages (Dunn 1994: 7-8), the dichotomy between public and private had come to mean separate notions, which in the seventeenth century England entailed the division between the common and the particular, that is, the difference between the public "commons" and privately owned lands. This became the basis for the public sphere, creating along the way the foundation for the liberal state. From the middle of the sixteen century onward, there developed a powerful ideology of the "common wealth", which stressed public utility and the good of the nation over that of private individuals. This idea is present in the prologues I focus on in this article, where the authors at times allude to fulfilling their duty to their country, as shown in what follows:

Some writers who have not truly worried about the welfare of their brothers are criticised (T. C. - I. D. - M. S. - T. B. 1656): "It is admirable to us, that our Country should be so much deluded, to build their practice upon such Authors that have not at all conduced to any considerable advantage in this so necessary useful Art as the preserving of mankind. Alas!"

In another excerpt (Sermon 1671), the importance of the author's national identity is stressed: " ... and have also digested this Work into a small volume, for no other design nor cause, but for the use and benefit of my Country." Likewise, in another preface (Barret 1699) it is affirmed that "The Art itself is particularly recommended of God, and has been valued and esteemed by all the wisest of Nations." 
In any case, the creation of a bourgeois public sphere brought with it important changes to the concept of political and literary authority. If, for the medieval writer, authority was a textual inheritance, a finite set of authorities who could be copied or adduced, for the late seventeenth writer there emerges a new system of authorisation. Now the writer's primary rhetorical concern is to demonstrate that he or she possesses common sense, and that he or she takes authority by representing the audience while trying to reveal the importance of the work they are about to introduce. In the titles that comprise my corpus, the reader is able to perceive clearly the aim of the book with regard to informing, explaining and even justifying the contents exposed there. These components are interwoven in the general explanatory mood that prevails in the text, as far as the writers try to justify the medical and, also, human significance of the manuals they present to readers. More than representing the traditional figure of the compiler, whose main role was copying, modifying (either by excerption, accretion or paraphrases), or just translating from another language, the author of these prefaces is concerned about uttering a useful message. He intends to teach the reader the art of midwifery based in most cases on his experience as a practitioner. The writer offers reasons about the necessity of a new manual, due always to an alleged deficiency of previous ones. Even if he invokes the presence of traditional authorities, acknowledges God's benevolence as a blessing for his travails, and shows a humble temperament, he is confident in the end of his presenting the reader a valuable and practical guide.

For the recognition and description of schemes, which can be defined as "forms of argument that capture stereotypical patterns of human reasoning" (Walton 2005: 1), I first follow Meyer's (1985a: 16) approach to the primary levels of expository text, where she distinguishes: (1) the sentence or microproposition level, which is concerned with the way ideas are organised within sentences, and the way sentences cohere and are organised within a text; (2) the macropropositional level, which relates to issues of logical organisation and argumentation; and (3) the top-level structure or overall organisation of the text as a whole.

At the macrocomposition level, the concern is with the relationships among ideas represented in complexes of propositions or paragraphs. The relationships at this level tend to be logical or rhetorical. In this study, I focus on the main rhetorical organisation of the prefaces. Since all the authors are worried about the current state of the medical practice when aiding labouring women and their newborn children, their yearning is to set forth a more precise guide than former ones, which enlightens both physicians and midwives in this delicate endeavour. In this line, I have chosen causation as the top-level structure that governs the other rhetorical relationships also present in the texts. As said before, the writers of these prefaces are deeply preoccupied about justifying the importance 
of the contents that readers are about to acquire. It does not deal with just another apprentice manual that practitioners should be acquainted with; on the contrary, the motives they explain, as the real consequence of all the previous bibliography they have known about and dare to criticise, entail the real grid of the prologue.

Apart from the causal scheme, I also depict other subordinate reasonings that enhance the motives for the writing. All these rhetorical relationships are nurtured with the appearance of some communion figures aimed at addressing and identifying shared values between the author and his audience. For the study of these figures, I consider Perelman and Olbrechts-Tyteca's (1969) classification of ways of thinking in their New rhetoric, and its revision by Graff and Winn (2006). Perelman and Olbrechts-Tyteca's work systematises different argumentative devices that can be deduced from previous groups of common places compiled by classical tradition, analysing and evaluating arguments used in everyday and legal discourse. In this manner, Perelman's main concern (Frogel 2004: 171) deals with the practical reasoning that is related to values. In this sort of estimation, there exists a segment of rational thinking and argumentation that cannot be reduced to logic or empirical methods. "The new rhetoric", therefore, calls attention to the notion that we can encounter rational arguments that are, however, neither logical nor empirical.

In the rhetorical model, we must first identify and understand the sentence structure and its integration into larger units, which make possible the recognition of semantic relations, and which comprise a contextual dimension that includes the figures of the addresser and addressee in the communicative act. To this respect, rhetorical argumentation (Martínez-Dueñas 2002: 25) is based on the development of units of information that are to appear in the textual representation. This representation, which in the present instance largely addresses the reader about the importance of following the book indications, holds a mainly expositive structure. This exposition is supplied with those argumentative devices that I am showing below, which both enrich the reading and improve the understanding, as much as the author's purpose requires of the readers' awareness for the comprehension of the manuals.

\section{Corpus description}

The texts of this research constitute a corpus of seven seventeenth century English prefaces belonging to treatises of midwifery. They have been collected from the Early English Books Online (EEBO) catalogue. All of them are first editions, written by practitioners and medicine students. As to their extension, the prefaces are about two and fifteen pages long. 


\section{Analysis of the rhetorical relationships}

The causal relationship between ideas shows one idea as the antecedent or cause and the other as the consequent or effect. The relation is often referred to as the condition, result, or purpose with one argument serving as antecedent and the other as the consequent. These arguments are before and after in time and causally related (Meyer 1985b: 271). In the causation relationship, there are two types: the covariance and the explanation. If the covariance presents equally weighted arguments, in the explanation, where the antecedent conditions or principles are subordinate to the consequent, the event or idea is explained. In the preface I find a most evident covariance relationship, in which the antecedent corresponds to a previous state of affairs about the need of help when delivering a child, and the consequent matches the necessity of depicting a treatise for those professionals, mainly midwives in this instance, who can accomplish such a beautiful and responsible duty. Reasoning and explaining, in this way, relate to everyday notions immersed in familiar, practical contexts. "Reasoning' covers the roughly overlapping notions of 'arguing' and 'justifying', as well as inferring" (Wright 2002: 34).

The outline of this first and most important reasoning can be represented as follows:

$$
\begin{aligned}
& \text { Causation - equal level in the content structure } \\
& \text { causation } \\
& \overline{\text { antecedent } \quad \text { consequent }} \\
& 12
\end{aligned}
$$

Figure 1. Format for the rhetorical relation of causation - covariance

Inserted into the causation narrative, other important subordinate reasonings are embedded either in the antecedent or the consequent analysis. I italicise the following:

3.1. Midwifes practice: or, a guide for women in the high concern of conception, breeding, and nursing children (Chamberlain 1665)

Causation: covariance, antecedent

Causation: covariance, consequent (led to) 
Causation: covariance, antecedent

"Concerning the excellence of the subject, it being a matter of the highest Concern, and so sublime Philosophy; and having observed the want of a Treatise of this Nature, seeing there is nothing of it complete, but deficient, ignorant and imperfect..."

Causation: covariance, consequent

"My desire of the general good, the preservation of the beauty of Nature in the progress hereof, and the safety and well being of both Mother and Infant; that both Root and Branch, tree \& fruit may flourish: these motives I say induced me to... this ensuing Treatise..."

In this first extract, the most worthy relationship is the causal one. The author considers the enormous importance of the issue under discussion and, bearing in mind the scarcity and deficiency of former studies about this matter, he states his wish for enlightening the mysteries of conception and procreation.

3.2 The expert midwife or an excellent and most necessary treatise of the generation and birth of man (Rueff 1637)

Causation: covariance, antecedent

- Response: question/ answer

Causation: covariance, consequent (led to)

$$
\begin{gathered}
\text { Response - equal level in the content structure } \\
\text { response }
\end{gathered}
$$

\begin{tabular}{cc}
\hline question & answer \\
\hline 1 & 2
\end{tabular}

Figure 2. Format for the rhetorical relation of response

Causation: covariance, antecedent

"The unskilfulness and want of knowledge in the midwife in matters both concerning the mother and the infant, does questionless oftentimes endanger the lives, both of the one and the other..."

Response: question/ answer

Questions: ... is it better that millions should perish for want of help and knowledge, or that such means, which though lawful in themselves, yet may by some be 
abused, should be had and used? Do we not see in many cases, that those things which otherwise were monstrous, are yet by necessity made tolerable? Or shall we because some good things are by evil men and evil minds abused, therefore deprive the good, of the use of good things?

Answer: if such slender reasons as these might prevail, then might there perhaps a great number perish, before ever they saw the light, who otherwise might live and increase the number of Gods church by their offspring, and perhaps also a great deal more work might be made for men midwives ...

Causation: covariance, consequent (led to)

"Mi intentions herein are honest and just, and my labours I bequeath to all grave, modest and discreet women, as also to such as by profession, practise either Physics or Surgery. And whose help upon occasion of extreme necessity may be useful and good, both for mother, child, and midwife ..."

In this preface, the response argument is similar to the causation in that the questions are before in time and the answers pose for the solution of the reasons inquired. They are set into the antecedent, developing the idea that the danger for prospective mothers is great and, therefore, it is necessary to find alleviation for their suffering. Although knowing the existence of prior works about midwifery, he argues that he offers something else "which will much strengthen [his] endeavours". And by questioning the evil misuse of some practices, he hopes for a better employ in the future.

\subsection{A directory for midwives, or a guide for women (Culpeper 1651)}

Causation: covariance, antecedent

- Description: setting trajectory

Causation: covariance, consequent (led to)

Description - unequal level in the content structure. Descriptive arguments are subordinate (includes manner, attribution, specific, evidence, equivalent, settings and identification)

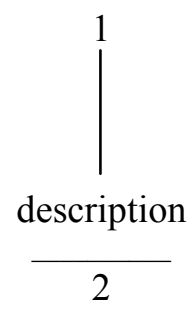

Figure 3. Format for the rhetorical relation of description 
Causation: covariance, antecedent

"I confess many Excellent Books have of late been printed in our own Mother Tongue, I cannot choose but commend those who though they cannot do what they would, yet are willing to do what they can ..."

Description: setting trajectory

... God preached to Noah, and the Old World rejected him; but the Devil entered into Judas, and the High Priests embraced and rewarded him: If you would know where the Devil keeps his Court, it is in this world, he is the Prince of the power of the World.

... In this world the Devil has his Agents, and their Actions are to keep you in Darkness, and so they will do, till Michael and his Angels fight against Sorath and his Angels ...

Causation: covariance, consequent

"For my own part I could have written you deeper notions in Physics than you find in this Book, but I write for children... Use what I have written, but abuse it not. If it be childish, it is like its mother..."

In this preface, there emerges an important argument that is usually inserted either in the antecedent or the antecedent. I refer to the description, which relates a topic to more information about it. All descriptive relations contain the same format in the content structure and are subordinate to the topic. In this example, I refer to the description setting relationship of trajectory. This gives a list of different times or locations that match a time index and reflect changing background of characters or ideas. The historical rigor of these ideas is not precise, as far as the author is trying to summarise God's requests to different biblical characters as to the Devil's peril.

3.4. Speculum matricis hybernicum; or the Irish midwives handmaid (Wolveridge 1669)

Causation: covariance, antecedent

- Description: setting trajectory

Causation: covariance, consequent (therefore)

Causation: covariance, antecedent

"It may perhaps be wondered why the author should expose his book ... more to be admired, that he should expose it to be tumbled, and searched by the accustomed, ingenious censure, and scrutiny, not only of the learned scholars, but of Grave Matrons, and Expert Midwives...” 


\section{Description: setting trajectory}

“... Mind a story related by as Learned a Physician as our age has known... The Story is this; There was an Irish woman, wife to a Common Soldier, who, though with child, accompanied her Husband in the Camp..."

\section{Causation: covariance, consequent}

"It will therefore be concluded... and undertaken by the author, because, in all his readings of authors... he had not seen any that had written in so plain and perspicuous a method... and suitable schemes in various figures, sufficient to direct and inform Midwives in their office..."

In this example of trajectory description, the author introduces the story of an Irish soldier's wife that accompanied her husband in the battlefield, pregnant with his child, and gives birth to twins. As if trying to encourage the Irish woman's will and disposition, the author offers this illustration as praise for the prospective mother, though hopefully aided by an expert midwife.

\subsection{The complete midwives practice (T. C. - I. D. - M. S. - T. B. 1656)}

Causation: covariance, antecedent

- Description: specific

Causation: covariance, consequent (led to)

Causation: covariance, antecedent

"It is high time, there being already published, many treatises in this kind... and find them strangely deficient, so crowded with unnecessary notions, and dangerous mistakes, that we thought fit to give you warning of them, that for the future the unfortunate practitioners may prevent the almost guilt, of the crying sin of murder..."

Description: specific

"... there has been reasonable intention in the publisher of some books, viz. the Birth of Man, the most ancient, but very much unfurnished; as also the books of child-birth, the expert Midwife, the worst that have been written, in French..."

Causation: covariance, consequent

"The chief occasion of this book, is to make it great exemplary, and school, where medicine married to the Midwives' industry, may teach every one the admirable effects of the divinity of this art of midwifery..." 
In this preface, it is worth commenting another description relation that is predominant in the texts I am considering. The specific description gives more precise information about something that was stated in a general way, going in this case from statement to examples. The author, in this extract, offers some titles of previous manuals as worse fitted, more imperfect works to his current endeavour. In this argumentation from the example, a particular case is backed up in order to emphasise the writer's endeavour and usually allows the reader to observe one example in the light of another, adjusting one's understanding of the first when deepening into the second (Olmsted 1997: 241).

\subsection{The ladies companion or the English midwife (Sermon 1671)}

Causation: covariance, antecedent

Causation: covariance, consequent (led to)

- Description: specific

- Causation: explanation (the reason, for)

$$
\begin{gathered}
\text { Causation - unequal level for explanation } \\
\text { causation }
\end{gathered}
$$

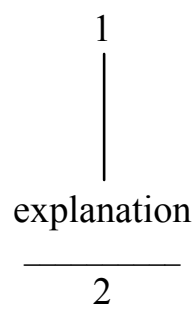

Figure 4. Format for the rhetorical relation of causation - explanation

Causation: covariance, antecedent

"The serious consideration of the intolerable misery that many Women are daily incident to, occasioned chiefly by breeding and bringing forth children; and the want of help in such deplorable conditions, by reason of the unskilfulness of some which pretend to the Art of Midwifery... has been one principal motive to me at this time..."

Causation: covariance, consequent

"... I have presumed with all dexterity possible to demonstrate in short, the most facile or easiest Directions for Women in their greatest Extremity, faithfully discovering to them, the sure and true means of help." 
Description: specific

“... It is very well known, that I have always had good success in my practice... Perhaps far more then they do at my pills, wherewith I cured that great Prince George the late Duke of Albemarle..."

Causation: explanation

"But the reason of which malice against me and my Medicine, may be discerned without a perspective-glass, for had it not perfectly cured his grace of the dropsy... and hundreds before and since, and still effects miraculous cures, there would not have been one word mentioned against the Pills..."

In this extract, the specific description relation provides an important example derived from the consequent. As a result of his fame as a physician, he knows that there exists some malevolence against him and his noble occupation. An indication of the efficacy of his pills is his cure of Great Prince, the late Duke of Albemarle.

Included within the consequent covariance as well, the explanation of an event or idea as another causal relationship is also justified in the preface. The author tries, with this reasoning, to justify the ill feeling against his pills due to the nobleman's cure and others'. He dares to accuse some "artificers" of copying his pills. In this case, the explanation is introduced by the noun phrase the reason and the conjunction for.

3.7. The companion for midwives, child-bearing women, and nurses (Barret 1699)

Causation: covariance, antecedent

- Description: specific

Causation: covariance, consequent (therefore)

Causation: covariance, antecedent

"The treatise I here present you with contains a Description of all the indispositions of women with child and in childbed, with the art of well practising midwifery and nursing. I have backed everything with examples from my own practice; which I chose rather to follow that the common road of Books upon that Subject."

Description: specific

Soon after Moses's History we are informed that Podalius and Machaon son to Esculapius himself drew teeth and dressed wounds; Appolo was an Oculist. Hippocrates not only understood surgery, but practised it; and Celeus the same. 
Among the Arabians the chief surgeon was Albucasus ...

I find every page of the Scripture full of instances of God's tenderness to children, his care in regulating their growth from their conception to the time of their birth, his countenancing and encouraging Midwives of a sincere honest Principle, and his detestation of such as dealt deceitfully with poor women, or acted cruelty to the innocent Babes.

Causation: covariance, consequent

\begin{abstract}
"Therefore I have not only given plain and familiar directions how she is to behave herself in the whole course of her attendance; but have endeavoured to press her to her duty, with such moral considerations as no true Christians ought to fly..."
\end{abstract}

In this piece, the main relationship that develops from the covariance causal relationship is the specific description. Different types of examples depict several groups of concepts starting from the aim stated in the antecedent of the covariance causal relationship. In the first instance, the author includes personalities that have developed the Art of Surgery. In the second, the author refers to exemplars of infancy encountered in "Holy writing" as a tribute to the innocence of childhood before focusing on a long excerpt from the Genesis book.

\title{
4. Analysis of the figures of communion
}

Perelman and Olbrechts-Tyteca (1969: 51) state that the speaker tries to establish a sense of communion that includes particular values recognised by the audience. As a consequence, he or she uses the total display of means available to the rhetorician for purposes of amplification and enhancement. Communion is used in a very general sense as the term denoting a community's agreement in questions of value, but also, more narrowly, as an objective sought in certain forms of discourse and as an effect of specific linguistic stylistic devices (Graff - Winn 2006: 46). In this sense, Perelman states that argumentation is conditioned by the audience it is addressed to and, therefore, should be adapted to it. The order of the ideas is essential because the changes in the readers are both effective and dependent. The readers' unity is visible in the speaker's selection of premises, but is made prominent through the use of devices such as the quotation, the allusion, and the proverb, among others, which recall shared traditions or a shared culture (Graff - Winn 2006: 63-64). Plantin (2009: 333) affirms, to this respect, that communion entails the final stage in which "a state of 'persuasion"" is attained through the union between the orator and his audience.

In the prefaces, the authors share the omnipresent religious feeling that surrounds all facts of their living time as one of the sources that they use to predispose the reader favourably. Some figures of communion get fused with the ap- 
pearance of certain topoi that also appear in modern ones, and which can be considered a rhetorical attitude with regard to the influence on the readers' auspicious disposition. God still appears as the only fundamental religious source to whom these authors acknowledge either to ask for blessings or to serve unconditionally, especially in the closing fragments of the prologues. It remains one important topos already present in medieval prefaces, and sustains an allpervading presence in the texts I am considering. Some examples are the following:

The final lines of one preface (Culpeper 1651) allude to possible mistakes com-
mitted by the author, declaring that "if it be good, let the Father have the praise,
its corruption it hath drawn from its mother: if you be Godly, viz. like God, you
will accept the will for the deed; and let such as are so know, that I am their Ser-
vant, and called by name Nich. Culpeper."

By the end of another text (T. C. - I. D. - M. S. - T. B. 1656), the writer concludes that he has no more to write, but refers the book to the reader, "desiring a blessing of God on these our faithful endeavours", and being the hearty well-wisher of his or her good.

Similarly, in another prologue (Sermon 1671) divinity is invoked by exclaiming: "For I call God to witness, that I never divulged the secret to any man breathing, though I have taken care that for the good of after-ages it shall not dye with me", and finishes his explanation by asking "to be protected by the Almighty God, and to live above the censure of malicious men ...". In the last excerpt (Barret 1699), the writer is convinced that he is serving "[his] Creator in a Conscientious Discharge of what [he understands] to be [his] Duty."

Another topos is the humility topos, wherein the authors claim their modesty before presenting the important data they are delivering. The classical modesty allows the author more rhetorical power as he manifests less physical, social or political power (Dunn 1994: 6), as in the following examples: "I have viewed over this work, and acknowledge it as my own child begotten in me by the Eternal Providence of God, errors mentioned in the Errata excepted..." (Culpeper 1651). Another one (Barret 1699) states that "it may not only be accounted Arrogance and Presumption, but impertinent folly, and unprofitable endeavours in the Author; either to think to outdo former writers... or outwit the other. Assuring you, therefore, that his aim is at neither, he it will be candidly received by all." A different writer (Sermon 1671) affirms that, "though of all men as [he is] the most unworthy, (as vulgarly by some envious persons accounted) so the less able to expose [himself] to so public a view, especially among the empty-pated and railing Empirics of these times, who make it their only concern to scoff, and make scandalous Libels, \&c. against matters of the greatest Truth." Finally, in this excerpt (Barret 1699) the author reflects that 
"the Design [he] had before [his] eyes, in writing this plain and familiar treatise, would not allow of any such gaudy accoutrements."

In the case of communion figures, I first refer to those related with a specific cultural background, as is the case of maxims and proverbs. Perelman and Olbrechts-Tyteca (1969: 166) describe them as the succinct expressions of values that command respect within a community. Whereas the maxim expresses a norm or value judgement, the proverb is a special sort of maxim, a short statement that particularises a value judgment, thereby "illustrating a standard". In these instances, the presumption of agreement is strong, since they are said to be the characteristic or formulaic expressions of a culture's "proverbial wisdom" (Graff - Winn 2006: 54). In the extracts selected, they try generally to strengthen an idea just posed as an illustration adding to the reader's comprehension:

In the example below (Culpeper 1651), the author warns about the dangers of the hovering evil at the beginning of his text in this sort of catchphrase which, according to Perelman and Olbrechts-Tyteca (1969: 167), is designed to secure attention through the rhythm and their concise and easily remembered form. They are adapted to particular circumstances, require constant renewal, and are too recent to enjoy the wide traditional agreement granted to proverbs: "The Fountain is the Principal of the Stream, yet may the water by muddy in the Stream, which is clear in the Fountain." He clarifies this notion a bit further in what could be seen as another tag: "This is most true, that the Devil is the Prince of Darkness, Darkness the Father of Ignorance, Ignorance the Father of Sin, and it is the Devil Black Boy by which he rules the World." So as to attack the sin of Envy, another preface (Sermon 1671) shows this popular proverb: "Yet notwithstanding the great rage of black mouthed Envy, that barks but cannot bite...".

The idea of communion is also present in another set of techniques, namely, allusions and quotations, which make reference to a common culture, tradition or past (Perelman - Olbrechts-Tyteca 1969: 177). They concern centrally the readers' recognition of a frame of cultural reference they share with one another and with the speaker employing them. It is important for the argumentative force to occur that there exists a community supporting the allusion or quotation. Therefore, the presumption of agreement over values is in this case involved, where it is often expressed some core principle thought by the speaker and the community as a whole to be particularly well articulated in the source text (Graff - Winn 2006: 56).

An allusion brings into focus a historical event or cultural fact without actually naming it, relying on the audience to recognise the reference. A quotation uttered without identifying its author or source works in the same way. Indeed, in the prefaces it is especially rich the use of quotations to reinforce or illustrate 
an idea, but in most cases it appears with the name of the author as a remainder of prestige and high-esteem. In these instances, I consider these attributed quotations as arguments from authority. This type of reasoning, traditionally influenced by the authority's reputation, uses his or her words and acts as a means to adhere to one's thesis, and tries to link two dissimilar realities. One reality is more explanatory and necessary than the other and needs to be reinforced, in this instance, by the authorial presence "held in shared reverence" (Harris 2008: 6) by both writers and readers.

In the texts I find a group of authorities related to medicine and philosophy. In this line, one author (Sermon 1671) cites "that famous Physician Dioscorides, under the great Queen Cleopatra". Another instance (Barret 1699) quotes from Seneca, referring to him as "a heathen better principled than many called Christians". Yet there is also praise to the "Holy writing", the author stating that he finds "every page of the Scripture full of instances of God's tenderness to Children", sustaining the idea that not only respected persons and deities but also texts like the Bible can have the same merit (Liu 1997: 417). This is reinforced by a long quotation of the Genesis book, about Marriage and the capacity of having children. Yet this lengthy passage turns into a more proper narrative with an enlightening, didactic purpose: "God said, let us make Man according to our likewise. Thus, God created the Man in his Image; and he created him Male and Female...”.

\section{Conclusions}

With this account of techniques and figures, I have shown the main elements that comprise the rhetorical organisation in this selection of Early Modern English prefaces, dedicated to midwives and their ministrations. In the texts, the authors seek to offer a useful guide to the reader, both male and female, based on the previous practice of midwives and surgeons that have attended to labouring women and their babies. In this particular case, the empirical assessment of the ingredients exposed there tries to be reinforced by the introductory part of the book, in which the reader is urged to follow carefully the writer's indications on behalf of the wellbeing of future mothers and children. The author is granted, therefore, an authority that he did not possess before, relegated to his previous task of assembler of records but without a critical opinion about the contents presented.

With a view to justifying the reading of the manuals, the writers have used several argumentative schemes so as to try to influence the reader's stance as regards the importance and utility of their reading them. When trying to outline the work's rationale, the most evident rhetorical relationship has been the covariance causation, by which the authors have defended the necessity for a use- 
ful treatise and have offered, as a result, the motives for such dissertations. Deriving from this reasoning, wherein an antecedent precedes a consequent, other rhetorical relationships have added to the instructive manner of the prologue. Another causal argument has been the explanation, supporting either the antecedent or the consequent by inserting some detailed information. Moreover, I have also underlined the use of the response argument that poses some questions and answers. The last essential reasoning worth analysing has been the description, distinguishing two types of descriptive relations: (1) The description as setting trajectory, which presents a sequence of characters in a more or less located time, with a main enlightening, illustrative purpose. (2) The specific description, which provides the reader with varied examples that endorse or reject the point of view debated at that moment. The prologue, accordingly, remains an essentially expository discourse, nurtured with some rhetorical figures that also aid in the argumentative impact.

As to the study of figures, I have especially regarded the figures of communion, representative of the preface since earlier times and still used in the modern prologue. I have highlighted the acknowledgement to God, though not begging for strict vigilance as in the medieval period, and the humility topos, as two commonplaces that seem to attract the reader's good nature. Communion has been present as well with the reference to some maxims and proverbs and, most importantly, with the use of the argument by authority to the detriment of the mere quotation, which does not usually identify its provenance. This particular device reinforces the value of the contents and bestows some prestige on them.

\section{REFERENCES}

\section{PRIMARY SOURCES}

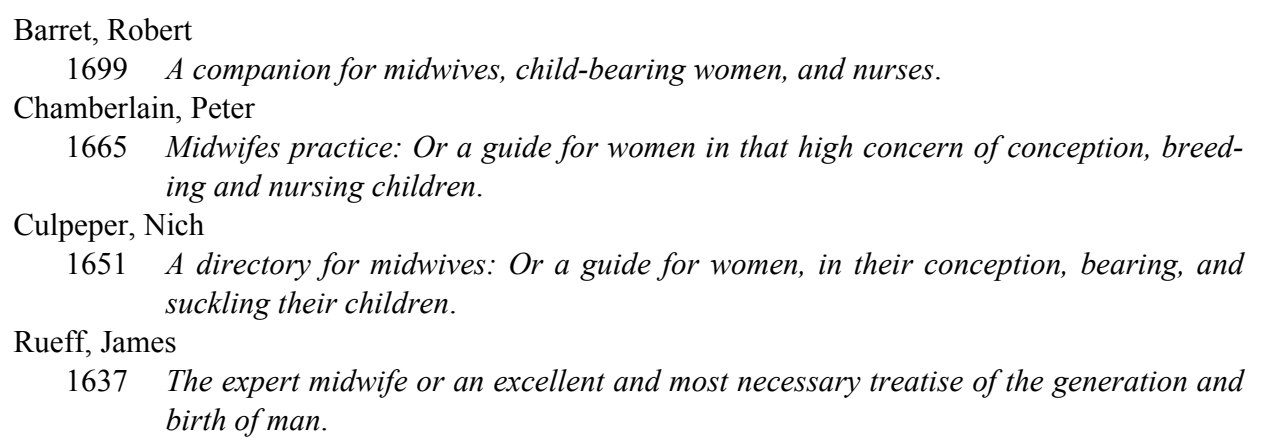


Sermon, William

1671 The ladies companion or the English midwife.

T. C. - I. D. - M. S. - T. B.

1656 The complete midwives practice, the most weighty and high concernments of the birth of man.

Wolveridge, James

1669 Speculum matricis hybernicum: Or the Irish midwives handmaid.

\section{SECONDARY SOURCES}

Britton, Bruce K. - John B. Black (eds.)

1985 Understanding expository text. A theoretical and practical handbook for analyzing expository text. Parts 1 and 2. New Jersey: Lawrence Erlbaum Associates.

\section{Dunn, Kevin}

1994 Pretexts of authority: The rhetoric of authorship in the renaissance preface. Stanford: Stanford University Press.

Evans, Ruth

1999 "An afterword on the prologue", in: Jocelyn Wogan-Browne - Nicholas Watson Andrew Taylor - Ruth Evans (eds.), 371-378.

Frogel, Shai

2004 "Philosophical argumentation: Logic and rhetoric", Argumentation 18/2: 171-88.

Graff, Richard - Wendy Winn

2006 "Presenting 'communion' in Chaïm Perelman's New rhetoric", Philosophy and Rhetoric 39/1: 45-71.

Harris, Randy

2008 "Cognitive dimensions of the universal audience", available at http://www.arts.uwaterloo.ca/ raha/ (date of access: December 2009).

Jost, Walter - Michael J. Hyde (eds.)

1997 Rhetoric and hermeneutics in our time: A reader. New Haven - London: Yale University Press.

Liu, Yameng

1997 “Authority, presumption, and invention", Philosophy and Rhetoric 30/4: 413-427.

Martínez-Dueñas Espejo, José Luis

2002 Retórica de la lengua inglesa. Granada: Comares.

Meyer, Bonnie J. F.

1985a "Prose analysis: Purposes, procedures, and problems", in: Bruce K. Britton - John B. Black (eds.), 11-64.

1985b "Prose analysis: Purposes, procedures, and problems", in: Bruce K. Britton - John B. Black (eds.), 269-304.

Olmsted, Wendy

1997 "The uses of rhetoric: Indeterminacy in legal reasoning, practical thinking, and the interpretation of literary figures" in: Walter Jost - Michael J. Hyde (eds.), 235-253.

Perelman, Chaim - Lucie Olbrechts-Tyteca

1969 The new rhetoric. A treatise on argumentation. (Translated by John Wilkinson Purcell Weaver.) Notre Dame, Indiana: University of Notre Dame. 
Plantin, Christian

2009 "A place for figures of speech in argumentation theory", Argumentation 23/3: 325337.

Walton, Douglas

2005 "Justification of argumentation schemes", Australasian Journal of Logic 3: 1-13.

Wogan-Browne, Jocelyn - Nicholas Watson - Andrew Taylor - Ruth Evans (eds.)

1999 The idea of the vernacular. An anthology of Middle English literary theory 12801520. Reed Hall: University of Exeter Press.

Wright, Larry

2002 "Reasoning and explaining", Argumentation 16/1: 33-46. 